\title{
Discursos sexistas no humorismo e na publicidade. A expressão pública, seus limites e os limites dos limites*
}

\author{
Luís Felipe Miguel** $^{* *}$
}

\section{Resumo}

Dois episódios ocorridos em 2011, no Brasil, obtiveram notoriedade por colocar em rota de colisão a liberdade de expressão e o combate ao sexismo: uma piada do humorista Rafinha Bastos sobre estupro e uma propaganda de roupas íntimas na TV. O artigo discute os dois casos, reconstituindo a polêmica e os argumentos mobilizados pelas posições em conflito. Conclui que, em ambos os casos, restrições à expressão se justificam, mas por motivos diferentes: a incitação ao ódio, num caso, e o baixo valor social da publicidade comercial, no outro.

Palavras-chave: Sexismo, Liberdade de Expressão, Humorismo, Publicidade Comercial.

\footnotetext{
" Recebido para publicação em 1 de setembro de 2011, aceito em 28 de junho de 2012.

*** Professor titular do Instituto de Ciência Política da Universidade de Brasília, onde coordena o Grupo de Pesquisa sobre Democracia e Desigualdades (Demodê), e pesquisador do CNPq. luisfelipemiguelgmail.com
}

cadernos pagu (41), julho-dezembro de 2013:95-119. 
Discursos sexistas no humorismo e na publicidade

Sexist Speeches in Humorism and Advertising:

Public Expression, Its Limits and the Limits' Limits

\begin{abstract}
Two episodes that occurred in 2011 in Brazil gained notoriety for putting on a collision course the freedom of speech and the fight against sexism: a joke about rape, by comedian Rafinha Bastos, and an underwear ad on TV. The article discusses the two cases, reconstituting the controversy and the arguments deployed by the conflicting positions. It concludes that, in both cases, restrictions on expression are justified, but for different reasons: the incitement to hate in one case and the low social value of advertising on the other.
\end{abstract}

Key Words: Sexism, Freedom of Speech, Humorism, Advertising. 
A edição de maio de 2011 da versão brasileira da revista Rolling Stone trouxe na capa o comediante Rafinha Bastos, que na época integrava o elenco do programa humorístico $C Q C$ na televisão. Bastos buscava firmar a imagem de "politicamente incorreto", com um humor ofensivo que não se detinha diante de qualquer parâmetro de bom gosto ou sensibilidade, como o título da reportagem já indicava: "A graça de um herege". E o primeiro parágrafo reproduzia uma piada particularmente agressiva que ele contava em seus espetáculos teatrais:

Toda mulher que eu vejo na rua reclamando que foi estuprada é feia pra caralho. [...] Tá reclamando do quê? Deveria dar graças a Deus. Isso pra você não foi um crime, e sim uma oportunidade. [...] Homem que fez isso [...] não merece cadeia, merece um abraço (Bastos, apud Rodrigues, 2011).

A reportagem causou razoável polêmica. Por um lado, grupos religiosos indignaram-se com a foto da capa, em que o comediante aparecia fantasiado de Cristo, com um coroa de espinhos na cabeça. ${ }^{1}$ Por outro, feministas viram na piada reproduzida no primeiro parágrafo um incentivo à violência sexual, que ultrapassava os limites da liberdade de expressão. $\mathrm{O}$ Conselho Estadual da Condição Feminina de São Paulo lançou uma nota de repúdio, o Ministério Público pediu a abertura de um inquérito policial e o humorista acabou prestando depoimento numa delegacia da capital paulista, para se defender da acusação de apologia ao crime.

Alguns meses depois, em setembro, um anúncio de televisão voltou a colocar em cena um conflito entre combate ao sexismo e liberdade de expressão. Estrelado pela modelo Gisele Bündchen, o comercial da Hope contrastava as maneiras "certas" e "erradas"

\footnotetext{
1 Ver, entre muitos outros, os sites http://fimdostempos.net/rafinha-bastossatirizou-jesus.html http://catolicosconservadores.wordpress.com/2011/10/10/opolemico-rafinha-bastos/ e http://holofote.net/humorista-rafinha-do-cqc-satirizoujesus-cristo-e-ainda-disse-agora-eu-quero-ver-o-que-vao-falar/.
} 
Discursos sexistas no humorismo e na publicidade

para uma mulher contar ao marido que fizera alguma bobagem (estourar o limite do cartão de crédito, bater o carro, convidar a mãe para morar com eles). A errada era simplesmente contar. A certa era fazer voz sexy, usando apenas calcinha e sutiã. Ao final, o locutor lia o slogan da campanha: "Você é brasileira, use seu charme". ${ }^{2}$

A Secretaria de Políticas para as Mulheres da Presidência da República (SPM) julgou que a propaganda era perniciosa $e$ ingressou com pedido junto ao Conselho Nacional de Autorregulamentação Publicitária (Conar) para retirá-la do ar. Segundo a SPM, o anúncio reforçava o "esteriótipo (sic) equivocado da mulher como objeto sexual de seu marido" (SPM, 2011:1). O Conselho, no entanto, determinou o arquivamento da petição por unanimidade, reconhecendo o apelo a estereótipos, mas avaliando que eram "comuns à sociedade e facilmente identificados por ela, não desmerecendo a condição feminina" (Folha de S. Paulo, 14/10/2011).

Os dois episódios colocaram em pauta problemas relativos à liberdade de expressão confrontada com formas de sexismo. A partir deles, o artigo busca pensar os limites da liberdade de expressão - um valor central na organização das sociedades democráticas, mas que pode conflitar com outros valores socialmente relevantes - para além da mera dicotomia "censura vs. ausência de censura".

$\mathrm{Na}$ primeira seção, faço uma breve retomada da argumentação clássica em favor da liberdade de expressão, que tem como autores canônicos John Milton e John Stuart Mill, para a partir dela indicar como o problema se coloca contemporaneamente. As duas seções seguintes descrevem os argumentos colocados em cena do debate brasileiro, primeiro em relação a Rafinha Bastos, depois em relação à campanha

2 Os vídeos podem ser vistos no Youtube: <http://www.youtube.com/watch?v=nk5H BdxMz8>, <http:/www.youtube.com/watch?v=8vyOpIHJzP4>e

<http://www.youtube.com/watch?v=Xb45-EC1Adk>. Acessos em: 18 nov 2011. 
publicitária da Hope. Na conclusão, por fim, argumento que, ainda que superficialmente similares, os dois casos trazem à baila discussões diferentes e que a defesa de uma limitação à liberdade de expressão se baseia, num caso, na proteção a direitos e, no outro, numa hierarquização dos tipos de discurso público.

\section{O valor da liberdade de expressão}

A ideia de liberdade de expressão, na forma como correntemente a entendemos hoje, é relativamente recente. Em geral, considerava-se que era dever do Estado e/ou da Igreja proteger seus súditos e fiéis da exposição a ideias nocivas. Se qualquer homem ou mulher é capaz de avaliar os produtos que estão à venda no mercado, escolhendo os melhores e descartando os piores, em relação às ideias não haveria igual discernimento. A censura estatal e eclesiástica protegeria, então, indivíduos incapazes de diferenciar, por si sós, o certo do errado. ${ }^{3}$

Uma exceção foi o experimento democrático da Grécia antiga. Os gregos possuíam a isegoria, o direito igual à fala na assembleia popular, que poderia ser apresentada como a contraface positiva da nossa liberdade negativa de expressão. Mas a isegoria não era exatamente uma garantia de livre expressão; ao contrário, estavam previstas punições para quem usasse de maneira indevida seu direito à fala.

$\mathrm{O}$ primeiro grande tratado em defesa da liberdade de expressão foi a Areopagítica, de John Milton (1999 [1644]). Motivado por um panfleto do próprio Milton em defesa do divórcio, o Parlamento inglês instituiu a censura prévia a todos os impressos. Com base, sobretudo, em exemplos clássicos (e também da Bíblia), o poeta respondeu com uma defesa da

\footnotetext{
3 Cumpre observar que a crença geral hoje é inversa. Como cidadãos, temos condições de escolher os discursos que melhor nos convêm. Mas, como consumidores, somos incapazes de avaliar a qualidade dos produtos. Por isso, são necessárias agências de vigilância sanitária, de certificação e de proteção ao consumidor.
} 
Discursos sexistas no humorismo e na publicidade

liberdade de expressão e de imprensa. Mas é uma defesa voltada sobretudo contra a censura prévia. O livro não fecha as portas à possibilidade de censura a posteriori.

A Areopagítica já desenvolve as duas linhas de argumentação centrais na defesa da plena liberdade de expressão, uma centrada no direito individual, outra na utilidade coletiva. A razão, concedida por Deus à humanidade, funda o livre-arbítrio, que significa sobretudo a possibilidade de escolher. "Quando Deus lhe deu [a Adão] a razão, deu com ela a liberdade de escolher, pois a razão é isso - escolha" (Milton, 1999:109). A censura é, assim, a negação de um dom divino, a liberdade de escolha.

Ao mesmo tempo, a busca pelo conhecimento, que é força motriz do progresso, depende da possibilidade de expressão também de ideias errôneas. Milton argumenta que mesmo obras reconhecidamente más devem ser permitidas, usando, como contra-exemplo, o dano causado ao cristianismo quando Juliano, - Apóstata, proibiu os cristãos de estudarem a cultura pagã (id.ib.:83). E expressa a convicção, presente em muitas das defesas iniciais da liberdade de expressão, que se todas as ideias forem expostas, a verdadeira sempre triunfará: "Quem jamais ouviu dizer que a verdade perdesse num confronto em campo livre e aberto?" (id.ib.:173). Assim, a liberdade de expressão não se impõe apenas pelo respeito devido a um direito individual; é também um imperativo do bem público.

Dois séculos depois, John Stuart Mill aprofundou o argumento em Sobre a liberdade, obra que faz da liberdade de expressão a pedra angular do liberalismo - em contraste, por exemplo, com a doutrina de Locke, na qual essa posição é ocupada pelo direito de propriedade. As liberdades correlatas de consciência, opinião, expressão e imprensa são sustentadas numa densa argumentação utilitarista, cujo núcleo é que "nunca podemos estar seguros de que a opinião que procuramos sufocar seja falsa; e, se estivéssemos seguros, sufocá-la seria ainda um mal" (Mill, 1991:61). 
Assim, Mill estabelece, em primeiro lugar, os "limites da razão": não temos como ter plena certeza da verdade. Aos nossos olhos, as execuções de Sócrates ou de Cristo são chocantes; mas foram feitas por homens que pretendiam sinceramente livrar o mundo de influências que lhes pareciam más (id.ib.:68). O que as gerações futuras dirão das vozes que tentamos silenciar hoje? A insegurança quanto à verdade exige tolerância quanto às opiniões que, aos nossos olhos e diante da maioria dos nossos contemporâneos, parecem perniciosas e inaceitáveis.

Em segundo lugar, Mill aponta que o espírito se fortalece "pela discussão e pela experiência" e deve haver discussão, para revelar "como se há de interpretar a experiência" (id.ib.:63). As doutrinas só mantêm a vitalidade quando confrontadas com doutrinas adversárias (id.ib.:82, 86) e a verdade ganha mais com os erros dos que pensam com as próprias cabeças do que com os acertos dos que só seguem aquilo que já está estabelecido (id.ib.:76). Insegurança quanto à verdade e necessidade de fortalecer o espírito por meio do debate convergem para afirmar o valor da liberdade de expressão. ${ }^{4}$

Stuart Mill permanece preso à ideia de que há uma "verdade", ainda que nunca possamos estar plenamente seguros de que nos assenhoramos dela. Leituras mais contemporâneas vão, antes, sustentar a defesa da liberdade de expressão no reconhecimento de que, na sociedade moderna, marcada pela "guerra dos deuses" weberiana, não há uma verdade que se sobreponha às divergências de crenças, de valores, de visões de

${ }^{4}$ É uma posição contrastante com a de Comte, pensador que Stuart Mill admirava, mas que via a liberdade de consciência como um resíduo que sobrevivia nas áreas em que o conhecimento científico ainda não se desenvolvera suficientemente: "Il n'y a point de liberté de conscience en astronomie, en physique, en chimie, en physiologie, dans ce sens que chacun trouverait absurde de ne pas croire de confiance aux principes établis dans ces sciences par les hommes compétents. S'il en est autrement en politique, c'est parce que les anciens principes étant tombés, et les nouveaux n'étant pas encore formés, il n'y a point, à proprement parler, dans cet intervalle, de principes établis" (Comte, 1895:53). 
Discursos sexistas no humorismo e na publicidade

mundo, de concepções de bem. Garantir a liberdade de expressão, dessa forma, não é proteger um método que nos permite uma aproximação à verdade, mas garantir a manifestação de diferentes posições, aceitas por princípio como sendo ontologicamente equivalentes. ${ }^{5}$

A liberdade de expressão foi entendida, em primeiro lugar, como tendo que se afirmar contra o Estado (e a Igreja). O entendimento de que o mercado também pode ser uma ameaça à liberdade de expressão - pelo silenciamento das vozes alternativas ou opostas aos controladores privados de meios de difusão - é posterior $e$, na verdade, permanece marginal. Como veremos, a discussão atual no Brasil (assim como em outros países) continua sendo, em grande medida, orientada pelo quadro "liberdade de expressão vs. censura estatal" (cf. Thompson, 1995:327).

Historicamente, foram afirmados quatro critérios principais para limitar a liberdade de expressão. Seria necessário limitá-la para combater a heresia, para preservar razões de Estado, para impedir a obscenidade ou para banir o discurso do ódio. É razoável afirmar que os três primeiros critérios estão muito esvaziados hoje e é o quarto, exatamente o que possuía menor importância antes do século $\mathrm{XX}$, aquele que possui maior ressonância no debate público atual nos países ocidentais. A tolerância à "heresia" é uma consequência necessária da tolerância religiosa (já que o dogma de um é a heterodoxia do outro), que por sua vez se impôs no Ocidente a partir da Reforma religiosa. A crescente desconfiança em relação aos poderes constituídos, que se associa ao entendimento de que a sociedade deve manter vigilância constante sobre as ações dos governantes, reduziu muito a esfera na qual se pode reivindicar legitimamente a

5 Cumpre notar que, a despeito disso, a argumentação de Stuart Mill sobre a nossa incapacidade de alcançar a verdade continua ecoando no pensamento liberal como base que justifica a liberdade de pensamento. É assim que Rawls, por exemplo, funda seu "pluralismo de doutrinas razoáveis" nos "limites da razão" - como nossa razão é limitada, doutrinas opostas podem ser, ambas, consideradas razoáveis e, portanto, legítimas (cf. Rawls, 1993). 
razão de Estado para cercear o fluxo de informações. $\mathrm{E}$ a maior elasticidade dos padrões morais, vinculada à percepção dominante de que as formas de desfrute erótico são questões de foro íntimo que não cabe aos poderes públicos regular, corroeu a base que sustentava a censura a materiais licenciosos.

Fica de pé o combate aos discursos que fomentam o ódio $e$ a violência contra determinados grupos sociais. É assim que as feministas antipornografia ressituam suas demandas: a defesa da proibição de livros, revistas ou filmes sexualmente explícitos não se sustenta mais no combate à obscenidade, mas no entendimento de que a pornografia é essencialmente um discurso de ódio antifeminino (cf. A. Dworkin, 1981; MacKinnon, 1993). Não pretendo, aqui, entrar na polêmica a respeito do feminismo antipornografia, mas apenas observar que seus argumentos parecem hoje mais dignos de consideração do que aqueles brandidos por seus aliados da direita religiosa, que permanecem presos à ideia de uma sexualidade regulada de forma impositiva. ${ }^{6}$

\section{O estupro das feias}

O primeiro caso que nos interessa aqui, o da piada de Rafinha Bastos sobre estupro, serviria também para estudar o impacto das novas tecnologias da comunicação na formação de redes de mobilização e ativismo. A reportagem da Rolling Stone repercutiu um pouco na mídia tradicional e muito em blogs, microblogs e redes sociais. $\mathrm{O}$ comediante foi execrado pelo Brasil afora, nas "marchas das vadias" que aconteceram na época manifestações que tinham como alvo exatamente a violência sexual contra mulheres. A professora Lola Aronovich, que entre as

${ }^{6}$ O debate no interior do feminismo é amplo. A posição antipornografia é emblematizada pelas obras de Andrea Dworkin e Catherine Mackinnon citadas antes, bem como por Dworkin e Mackinnon (1988) e pela coletânea organizada por Cornell (2000). Para a posição oposta, ver Rubin (1981) e a coletânea organizada por Assiter e Carol (1993). Fora do feminismo, mas dialogando com ele, Ronald Dworkin (1981) sustenta uma posição liberal padrão. 
Discursos sexistas no humorismo e na publicidade

feministas ganhou estatuto de blogueira cult com seu "Escreva, Lola, escreva", iniciou uma petição de protesto contra Rafinha Bastos, que obteve pouco mais de mil e quinhentas assinaturas. ${ }^{7}$ Mas meu objetivo, aqui, não é mapear as reações à piada no mundinho da blogosfera (e twittosfera) progressista, e sim entender, a partir dela, algumas das questões vinculadas à expressão pública do preconceito, em geral, e no humorismo, em particular.

A defesa de Rafinha Bastos seguiu uma linha simples - e esperada -, que podemos chamar de "argumento do salvoconduto para o humor". O próprio humorista expressou o argumento com clareza exemplar, quando precisou depor na $14^{\mathrm{a}}$ Delegacia Policial, em São Paulo. Na ocasião, ele declarou: "É uma piada. A imprensa colocou como se fosse um depoimento, uma declaração e, na verdade, isso foi feito num ambiente teatral, no palco. Eu nunca dei um depoimento em um palanque para falar que eu era a favor da violência contra a mulher". E acrescentou que "todos têm que entender que eu sou comediante". 8

Meses mais tarde, motivados por outra tirada de péssima repercussão de Rafinha Bastos ${ }^{9}$, humoristas de outra geração apresentaram sua solidariedade corporativa, reforçando $\mathrm{o}$ argumento. Em entrevista ao jornal Folha de S. Paulo, instado a completar a frase "O limite do humor é...", Luis Fernando Veríssimo declarou: "Não deve ser nenhum" (Folha de S. Paulo, 5/5/2011). Jô Soares apresentara uma posição apenas ligeiramente

\footnotetext{
7 A petição continua disponível para leitura na internet, embora não seja mais possível subscrevê-la (<http://www.change.org/petitions/diga-a-rafinha-bastosque-sexo-e-estupro-so-diferentes-e-que-estuprador-merece-cadeia $>$. Acesso em: 5 nov 2011).

8 Giba Bergamin Jr., "Rafinha Bastos depõe em delegacia de São Paulo", Folha.com, 8/8/2011 (<http://www1.folha.uol.com.br/ilustrada/956347-rafinhabastos-depoe-em-delegacia-de-sao-paulo.shtml>. Acesso em 5 nov 2011).

9 No programa CQC de 19 de setembro de 2011, Bastos comentou a gravidez da cantora Wanessa Camargo e falou: "comeria ela e o bebê". A piada causou revolta e, sob pressão de anunciantes, a Rede Bandeirantes retirou o humorista do programa.
} 
mais matizada, falando expressamente do caso de Rafinha Bastos: "Eu só acho que o humor não pode ter limite. Quem estabelece esse critério é quem fala a coisa. A criação não pode ter limite". E acrescentou que "Há uma linha tênue entre humor e grossura [...]. Se tem graça, é humor. Se não tem, vira grossura. Se fosse uma coisa realmente muito engraçada, não teria nenhum problema" (Folha de S. Paulo, 22/10/2011).

É importante notar que o argumento do salvo-conduto para o humor não questiona a ideia de que o discurso do ódio representa um limite à liberdade de expressão. Apenas contrabandeia a percepção (simpática, mas evidentemente errônea) de que o humor é necessariamente inócuo e incapaz de propagar ódio ou incitar a violência. Então, se é assim, nós podemos até não gostar, achar grosseira, de mau gosto, a piada de Rafinha Bastos, mas não podemos culpá-lo por tê-la feito ou pretender proibi-lo de tornar a fazê-la.

Mas é necessário investigar como algo se credencia ao estatuto de "humor"; ou, pensando no nosso caso, o que faz com que alguém possa considerar engraçada uma piada sobre estupro. No início do seu estudo póstumo sobre a comicidade, o filólogo russo Vladimir Propp diz que "o riso ocorre em presença de duas grandezas: de um objeto ridículo e de um sujeito que ri - ou seja, do homem" (Propp, 1992:31). Deixando de lado a utilização do gênero masculino como universal para a humanidade, no final da frase, que não deixa de ser interessante no âmbito da presente discussão, podemos colocar uma questão adicional: o que faz com que um objeto seja entendido como "ridículo"? Há uma construção da "ridicularidade" desse objeto que mobiliza um grande conjunto de pressupostos sobre o que é a norma e o que é o desvio, sobre quais são os comportamentos normais e suas motivações. E o riso, embora tantas vezes seja saudado como "libertador", pode tanto desafiar quanto confirmar os discursos dominantes, os preconceitos e os estereótipos cristalizados.

Pensando no caso em tela: o estupro cometido contra uma mulher feia não é uma violência contra a vítima, mas uma 
Discursos sexistas no humorismo e na publicidade

gentileza que o estuprador faz a ela. O que é necessário mobilizar para que essa frase pareça dotada de graça? Saltam aos olhos dois elementos, aliás, intimamente ligados.

Em primeiro lugar, a percepção de que a mulher só existe para o homem. Não receber a atenção masculina equivale à morte para a mulher; assim, a atenção que é dada na forma de violência é um avanço em relação à situação anterior, de não-atenção absoluta. Em segundo lugar, o único atributo que torna a mulher merecedora dessa atenção masculina que a redime é sua beleza, isto é, a adequação aos padrões estéticos vigentes. Se ela é feia, ela não pode esperar receber atenção, e é por isso que qualquer atenção que venha a receber, inesperadamente, na forma de uma agressão sexual, só pode ser vista como uma caridade do estuprador. Existência apenas a partir do olhar masculino $e$ valorização prioritária da aparência são, aliás, dois elementos que há tempos o pensamento feminista aponta com centrais nos mecanismos da dominação masculina (cf. Beauvoir, 2009; Wolf, 1992).

Certamente é exagero dizer que a piada contada por Rafinha Bastos é um estímulo à prática do estupro - que vai motivar alguém a agredir sexualmente uma mulher. Mas ela colabora para estigmatizar aquelas que não se adequam aos padrões de beleza e, principalmente, reforça a ideia de que toda mulher deseja a atenção masculina e que, portanto, suas negativas são pro forma e podem (devem?) ser desconsideradas. O desprezo sistemático ao "não" feminino, interpretado como um "sim" envergonhado, é, como a literatura feminista tem demonstrado há anos, um dos vetores mais significativos da violência sexual (cf. Pateman, 1989).

Esse é o universo mental comum em que se movem Rafinha Bastos e aqueles que dele riem. Hoje talvez poucos terão coragem de verbalizar essa percepção sexista da forma crua que eu expus aqui, mas o humor serve exatamente como um território seguro para que ela se manifeste. Não é por acaso que o humor parece ser sempre o reduto final de sobrevivência dos discursos preconceituosos, quando eles não encontram mais legitimidade 
social para se manifestar de outra forma. Assim, o humor machista sobrevive ao machismo doutrinário aberto, o humor antissemita ao antissemitismo escancarado, o humor homofóbico ainda hoje tem curso mesmo em espaços sociais nos quais a homofobia assumida não é mais admitida e assim por diante.

No entanto, nem sempre é fácil traçar a linha divisória entre um humor crítico e outro preconceituoso. ${ }^{10}$ A piada de Rafinha Bastos é um caso pouco problemático, dada sua evidente ausência de qualquer intenção satírica. Sarcasmo e ironia implicam num discurso que tem a si próprio como alvo do humor e está sujeito a ruídos de interpretação por parte do público.

Um exemplo foi a recepção dada à personagem Amanda, do grupo Anões em Chamas, que representava uma mulher submissa, que aceitava todos os abusos do seu homem, num programa de conselhos para suas espectadoras. $\mathrm{O}$ primeiro episódio, veiculado na internet no início de 2010, dava dicas sobre como maquiar - literalmente - a violência doméstica. $\mathrm{O}$ espírito dos conselhos, sintetizado pela própria Amanda, era: "Mulher que apanha do marido fica solteira. Mas mulher que cai da escada ou bate com a cara no armário da cozinha fica casada, e pra sempre". ${ }^{11}$ O vídeo foi visto como "sério" por boa parte do público, levando ao cancelamento do canal dos Anões em Chamas no Youtube, por "violar a política do Youtube que proíbe a apologia ao ódio". O próprio grupo achou necessário se explicar - no episódio 4, após ensinar truques para fingir que é virgem, Amanda informa que a violência contra a mulher é crime e não pode ser tolerada. ${ }^{12}$

\footnotetext{
${ }^{10}$ Apenas para evitar qualquer mal-entendido: não estou pretendendo que as manifestações humorísticas se encaixem necessariamente em uma ou outra dessas categorias. Com certeza, boa parte do humor não é nem crítico, nem preconceituoso.

${ }^{11} \mathrm{Ver}<\mathrm{http}$ //www.anoesemchamas.com.br/amanda-episodio-1/>. Acesso em 6 nov 2011.

${ }^{12}$ Ver < http://www.anoesemchamas.com.br/amanda-episodio-4/>. Acesso em 6 nov 2011. Criticado por seus fãs pelo "recuo", o programa mostrou-se
} 
Discursos sexistas no humorismo e na publicidade

A polêmica em torno do vídeo da Amanda ${ }^{13}$ revela que mesmo um humorismo bem pouco sofisticado suscita indagações de difícil resposta. Trata-se de uma denúncia ou de uma banalização? O alvo da ironia é o agressor ou a mulher agredida? $\mathrm{E}$ o que deve ser levado em conta é a intenção do emissor ou a compreensão dos receptores? Em suma, se é possível conceder um salvo-conduto (embora não ilimitado) ao humor, ele não se baseia em sua inocuidade, mas em sua ambivalência, no fato de que, com frequência, o sentido último do discurso não está plenamente claro. Mas a piada de Rafinha Bastos não se credencia a lançar mão desse recurso.

\section{A submissão das belas}

O humor também foi invocado em defesa da campanha publicitária da Hope com a modelo Gisele Bündchen. A Secretaria de Políticas para as Mulheres, na representação dirigida ao Conar,

ambivalente nos episódios seguintes, culminando no oitavo e último, em que Amanda entrevista uma feminista, estereotipada como uma mulher masculinizada e mal-humorada (<http://www.anoesemchamas.com.br/amandaepisodio-8/>; acesso em 6 nov 2011). Foi a resposta à reclamação contra o programa que grupos feministas fizeram ao Ministério Público. Entrevistada em maio de 2010 no blog da jornalista Letícia Sorg, a atriz que interpretava Amanda não se furtou a dizer, a sério, que "o feminismo é uma coisa ultrapassada", que "perdeu toda a sua razão de ser" (<http://colunas.epoca.globo.com/ mulher7por7/2010/05/31/amanda-a-nova-\%E2\%80\%93-e-polemica-\%E2\%80\% 93-amelia/>; acesso em 5 nov 2011). Ao mesmo tempo, os blogs de apologia ao machismo, como o Testosterona, compraram o discurso de Amanda pelo valor de face, promovendo o programa como um reforço bem-humorado às suas próprias ideias. Para quem julga que as falas de Amanda são caricatas demais para que alguém as tome a sério, cf. a pregação da pastora Sarah Sheeva, da Igreja Celular Internacional, no chamado "Culto das Princesas" (Folha de S. Paulo, 12/11/2011).

${ }^{13}$ Parte dela pode ser vista nos comentários ao próprio vídeo, no site dos Anões em Chamas, ou ao post sobre o caso no blog de Lola Aronovich, em http://escrevalolaescreva.blogspot.com/2010/05/video-ofensivo-ouengracado.html (acesso em 7/11/2011). 
identificou a presença de estereótipos de gênero na propaganda $e$ sustentou a necessidade de bani-los, alegando que os estereótipos

mantêm formas de dominação e marginalização que
atingem grupos historicamente marginalizados. Os
comportamentos preconceituosos e violentos contra
mulheres decorrem justamente de uma cultura
discriminatória, patriarcalista e racista (SPM, 2011:2).

A argumentação, assim, segue uma linha vinculada ao argumento do discurso do ódio, bastante similar ao que apresentei em relação à piada de Rafinha Bastos do estupro, na seção anterior.

Já para o presidente da Associação Brasileira de Agências de Propaganda, a publicidade da Hope era "bem humorada, divertida"; o presidente da agência que a criou afirmou que levála a sério "chega a ser ridículo"; a assessoria da modelo classificou o anúncio de "uma sátira" e "algo que era para ser divertido" (Folha de S. Paulo, 29/9/2011). Um leitor, cuja carta foi publicada na Folha de S. Paulo, avançou nessa direção, pontificando que "o primeiro passo para o totalitarismo revela-se na perda da capacidade de rir" (Folha de S. Paulo, 1/10/2011).

Para além do humor, parte da crítica dirigida à ação da SPM confundiu - deliberadamente ou não - a argumentação apresentada, sobre como a propaganda representava a mulher como objeto sexual, com uma denúncia da utilização do corpo feminino como apelo publicitário, que, na verdade, nunca foi colocada em questão. Assim, o "Painel" da Folha de S. Paulo reproduziu o comentário atribuído a um "tuiteiro" anônimo: "Mais alguns anos de PT no poder e as mulheres bonitas serão obrigadas a usar burka (sic)" (Folha de S. Paulo, 30/9/2011).

O teólogo ultramontano e colunista de jornal Luiz Felipe Pondé dedicou um texto ao assunto:

Todo mundo prefere gente bonita à sua volta. $\mathrm{O}$ ambiente de trabalho fica muito melhor quando tem mulher bonita, cheirosa $e$ bem vestida por perto. [...] Claro que a raiva 
contra argumentos como esse nasce dos chatinhos. É a falta do 'recurso' contingente [...] que causa o rancor. Temo que uma hora dessas inventem uma cota de feinhas para as faculdades, as empresas e a publicidade. Ou que proíbam as mulheres de ficarem de calcinha em casa (Folha de $S$. Paulo, 10/10/2011).

O jornal $O$ Globo, em sua edição de $1^{\circ}$ de outubro de 2011, publicou na capa uma charge de Chico Caruso, com a ministra da SPM, Iriny Lopes, trajando apenas calcinha e sutiã e anunciando: "Querido, proibi o anúncio da Gisele Bündchen". Em entrevista a uma revista semanal, a ministra se viu confrontada à pergunta de se ela "teria agido por uma reação feminina de inveja à beleza da Gisele Bündchen" (IstoÉ, 12/10/2011).

A principal linha de argumentação, no entanto, vinculava-se à defesa da liberdade de expressão, pura e simples. Fernando Barros e Silva, ainda que reconhecendo o caráter sexista do anúncio, via "uma opção regressiva e autoritária pela censura", uma "medida obscurantista", perguntando: "Em nome de que a propaganda deve estar necessariamente em sintonia com valores progressistas ou submetida à visão igualitária da relação entre o homem e a mulher?" (Folha de S. Paulo, 30/9/2011). Ao lado da coluna, o editorial do jornal batia na mesma tecla (Folha de $S$. Paulo, 30/9/2011). Mesmo um ministro do governo Dilma Rouseff, Moreira Franco, manifestou-se publicamente contra a representação ao Conar (Folha de S. Paulo, 13/10/2011).

O argumento foi desenvolvido pela advogada Taís Gasparian, para quem o único limite válido para os discursos na esfera pública é o incentivo ao ódio e à violência. Afastado esse elemento, no caso porque a "imposição de única interpretação ao anúncio revela-se autoritária por não reconhecer a capacidade dos cidadãos de filtrarem o que há de humor e sugestão na mensagem", então

a publicidade insere-se no contexto da liberdade de expressão, não podendo ser proibida, sob pena de excesso 
de controle e infantilização da sociedade. Tentativas de regular os comportamentos sociais são próprias de uma sociedade fascista (Folha de S. Paulo, 11/10/2011).

Há força nessa linha argumentativa porque, de fato, enquadrar a propaganda da Hope como discurso de ódio parece abusivo. O que é necessário questionar, no arrazoado de Gasparian, é o estatuto concedido à publicidade comercial, em sua relação com o princípio da liberdade de expressão. $\mathrm{O}$ princípio não se estende indiferenciadamente sobre todos os tipos de discurso; ele os distingue de acordo com os valores que se julga que podem promover e também segundo seu alcance. É assim que o discurso jornalístico possui um dever de respeito à realidade factual, de acordo com sua deontologia profissional própria, que seria absurdo exigir do discurso artístico. Ou que o discurso científico precisa se adaptar a regras de construção das evidências que não são cobradas do discurso político.

A publicidade comercial possui uma posição especial, dado que não promove nenhum valor socialmente relevante $e$, ao mesmo tempo, possui enorme penetração, tendendo a colonizar todo o espaço público (Klein, 2002). Trata-se de um discurso eminentemente manipulativo, característica que se acentua a partir do momento em que a propaganda se divorcia do produto - em vez de vender suas pretensas qualidades, passa a vender uma imagem projetada sobre quem o consome.

É para proteger a sociedade de suas técnicas manipulativas que a expressão publicitária convive com múltiplas restrições - por exemplo, a legislação que coíbe a chamada "propaganda enganosa". Produtos considerados nocivos, como cigarros, bebidas alcoólicas e remédios, têm sua publicidade restringida (em termos de conteúdos ou de horários e locais de exibição), quando não proibida. Em países como a França, comerciais de refrigerantes ou outros alimentos com baixo valor nutritivo precisam incluir uma recomendação hipócrita em prol da alimentação saudável. Em muitos países, a publicidade dirigida a 
Discursos sexistas no humorismo e na publicidade

crianças é severamente controlada ou mesmo inteiramente vetada. Em suma, a liberdade de expressão do discurso publicitário convive com inúmeras restrições, todas aceitas como legítimas.

Os interesses ligados ao setor brandem o estandarte de uma "liberdade de expressão comercial" (Ferraz Jr. et al., 2000; para análises críticas, ver Rocha, 2007, e Lima, 2008). Principal porta-voz da ideia no Brasil, o Conselho Nacional de Autorregulamentação Publicitária é também um mecanismo de antecipação às críticas, garantindo que a propaganda é capaz de estabelecer e fazer cumprir seus próprios limites - uma espécie de raposa boazinha colocada para cuidar do galinheiro. Ainda assim, permanece o fato de que há um amplo entendimento de que o discurso publicitário precisa, sim, ser controlado de uma forma mais rigorosa do que outras formas de expressão, isto é, de que possui uma liberdade reduzida.

A questão que o comercial da Hope coloca, portanto, é se o sexismo está entre os conteúdos que devem ser coibidos na publicidade comercial ou não. Cumpre observar que a propaganda, na medida em que busca a adesão mais imediata de seu público, tende a trabalhar no sentido de reforçar estereótipos socialmente disseminados - ao ponto de que uma
pesquisa sobre a representação do papel dos sexos na publicidade, encomendada pelo Ombudsman dos Consumidores da Dinamarca, [terminou] sugerindo que se proíba toda e qualquer representação de seres humanos em anúncios (Vestergaard e Schrøder, 1988:194).

Assim, como regra, a publicidade tende a reforçar o sexismo, $e$ entre propagandas de lingerie, de cerveja ou de margarina as diferenças são mais de grau do que de qualidade.

É possível contrastar o caso da Hope com outro, ocorrido na mesma época. A Caixa Econômica Federal colocou no ar um comercial em que o escritor Machado de Assis era representado por um ator branco - não se sabe se por ignorância dos criadores, 
que não imaginavam que o escritor mais reverenciado do Brasil pudesse ser negro, ou por julgarem que o público estranharia o Machado "histórico". Após a denúncia da propaganda pelo movimento negro, a Caixa rapidamente retirou o anúncio do ar e o refilmou com um ator negro no papel do escritor (Folha de S. Paulo, 11/10/2011). Não se ouviram gritos indignados de "censura!", nem se invocou a liberdade de expressão. Ao que parece, portanto, a reação à SPM no caso do comercial da Hope revela, sobretudo, que parte da sociedade brasileira é mais tolerante com o discurso do sexismo do que com o discurso do racismo. ${ }^{14}$

\section{Conclusões}

Por que a piada de Rafinha Bastos é grave? Volto aqui à discussão sobre os limites da liberdade de expressão. O que está em questão é o ambiente social em que determinado discurso se encaixa. Se Bastos tivesse dito, por exemplo, que todos os jogadores de voleibol deveriam ser esbofeteados, isso seria certamente bobo, talvez grosseiro, provavelmente sem graça, mas também sem consequências, porque não temos, em nossa sociedade, modalidades de violência dirigidas de forma específica contra jogadores de vôlei. Mas temos, sim, a violência sexual contra as mulheres como um problema de primeira grandeza. E a banalização dessa violência, como Rafinha Bastos fez, é um elemento crucial para que ela se perpetue e para que os estupradores sejam punidos de forma tão débil.

Em suma, a piada é nociva e foge aos limites da proteção da liberdade de expressão pelo exato mesmo motivo pelo qual ela é considerada "engraçada" por seu público: porque ela participa de um universo mental em que faz sentido. Assim, ela é ativa; ela contribui para a perpetuação de uma situação em que o estupro é simultaneamente negado, minimizado e tolerado, com suas

\footnotetext{
${ }^{14}$ Isso não significa que o racismo tenha sido superado, apenas que estão banidas do discurso público legítimo mais formas de expressão aberta do racismo do que do sexismo (ou da homofobia).
} 
Discursos sexistas no humorismo e na publicidade

vítimas sendo estigmatizadas. Ela faz mal, não com palavras, mas com as ações que provoca. Ou seja, o problema da piada não está no que ela provoca em nós, que ficamos ofendidos; não está na nossa indignação e revolta. A essência da liberdade de expressão é que o argumento da "angústia moral", como dizia Stuart Mill, não é válido, e é por isso que eu, como ateu, tenho o direito de dizer que Deus não existe, por mais que isso magoe os crentes.

O problema, então, não está na ofensa provocada à sensibilidade de alguns, mas no que a piada de Rafinha Bastos provoca naqueles que acham graça dela; em como ela contribui para incitar, naturalizar ou legitimar comportamentos que ferem outros. É o caso de todos os chamados "discursos de ódio", da incitação à violência, e também, segundo estou argumentando aqui, dessa banalização do estupro. A partir do entendimento, correto, de que a banalização da violência contra a mulher (estendo aqui da violência sexual para abranger também a violência doméstica) é uma das causas centrais da sua reprodução, é possível justificar o banimento legal desse tipo de discurso da esfera pública.

O caso da propaganda da Hope também é grave, mas é incorreto tentar enquadrá-lo em termos de discurso do ódio, como fez a SPM em sua representação ao Conar. Tratava-se, ali, de avançar na redução à tolerância ao discurso machista, numa circunstância em que não havia nenhum valor socialmente relevante em risco - afinal, certamente existem maneiras de vender calcinhas que não passam pela afirmação ostensiva da estupidez feminina e da incapacidade das mulheres para obter qualquer coisa sem insinuar o oferecimento de favores sexuais. São, então, questões diferentes que justificam as ações contra Bastos, de um lado, e a Hope, do outro, ainda que ambas passem por uma aparente oposição entre a luta contra o machismo e a liberdade de expressão.

São questões delicadas porque a liberdade de expressão não é um valor que se descarte facilmente. Ela é essencial em si mesma e instrumental para a preservação de muitas outras 
liberdades democráticas. O caminho esboçado neste paper sempre se arrisca a levar à imposição de uma visão tida como certa, contra todas as outras diferentes, errôneas, inadequadas, desagradáveis. Se julgamos que o comercial da Hope deve ser retirado do ar, por que não aproveitar e censurar também os escritos de Luiz Felipe Pondé, citado na seção anterior, de um machismo ainda mais explícito e repugnante? Assim como precisamos entender os limites da liberdade de expressão, precisamos protegê-la, observando com cuidado os limites na aplicação desses limites.

É possível adaptar aqui uma distinção utilizada pelo filósofo liberal Ronald Dworkin, entre questões de princípio e questões de política. Questões de princípio são julgadas com referência aos direitos básicos, inalienáveis. As questões de política, por sua vez, são certas ou erradas de acordo com a avaliação das consequências que produzem (R. Dworkin, 2005). Como o mundo social é complexo, princípios e política com frequência se cruzam. Sem pretender resolver o problema, nem produzir um "critério" que magicamente o solucione de uma vez por todas ${ }^{15}$, indico como diretriz a ideia de que a liberdade de expressão é um princípio, necessário para a vida na democracia, ao passo que os limites a ela devem ser julgados como questões de política, pela análise dos custos $e$ benefícios que trazem - $e$, por mais frequentes que possam ser, sempre encarados com exceções a uma regra.

Trata-se de uma posição plena de armadilhas $e$ ambiguidades. Sem dúvida, a situação daqueles que simplesmente

\footnotetext{
${ }^{15}$ Nos debates sobre o tema, é comum que aqueles que reconhecem o conflito entre a liberdade de expressão e outros valores apelem para um critério superior que resolveria sem ambiguidade o problema - em geral, invoca-se a "dignidade humana" (e.g., Gomes, 2001). No entanto, tal critério é uma fórmula retórica vazia. A "dignidade humana" tem um sentido para o fundamentalista religioso, outro para a feminista, por exemplo. O conflito, que é político, simplesmente desloca-se para o significado dessa "dignidade humana". Julgo mais honesto $e$ também mais produtivo assumir o conflito de valores e a decisão política relativa a ele. Para uma teorização mais sofisticada, mas igualmente evanescente, da "dignidade humana", cf. Habermas (2004).
} 
Discursos sexistas no humorismo e na publicidade

afirmam o valor de uma liberdade ilimitada de expressão é bem mais confortável. Mas nos deixa com muitos problemas em aberto. Como vimos, Stuart Mill dizia que nunca podemos estar 100\% certos da correção daquilo em que cremos. Provavelmente ele estava certo. Mas o combate à violência sexual e ao sexismo são duas excelentes apostas, se queremos encontrar bandeiras justas para abraçar. A aceitação dos limites da liberdade de expressão, no contexto dos casos discutidos aqui, se vincula à opção política pela construção de uma sociedade igualitária para mulheres e homens.

\section{Referências bibliográficas}

AlmEIDA, Marco Rodrigo e FINOTTI, Ivan. Se não tem graça, piada vira grossura. Folha de S. Paulo, 22/10/2011, p.E-3.

ASsiter, Alison e CAROL, Avedon. Bad girls and dirty pictures: the challenge to reclaim feminism. London, Pluto, 1993.

Barros E Silva, Fernando. Abaixo o sutiã. Folha de S. Paulo, 30/9/2011, p.A-2.

BEAUVOIR, Simone. O segundo sexo. Rio de Janeiro, Nova Fronteira, 2009 [1949].

COMTE, Auguste. Plan des travaux scientifiques nécessaires pour réorganiser la société", reproduzido no "Appendice général, do Système de politique positive, t. 4. $3^{e}$ éd. Paris, Carilian-Gœury et Dalmont, 1895 [1822].

CORNELL, Drucilla (ed.). Feminism and pornography. Oxford, Oxford University Press, 2000.

DANTE FILHO. Painel do leitor. Folha de S. Paulo, 1/10/2011, p.A-3.

DWORKIN, Andrea. Pornography: men possessing women. London, The Women's Press, 1981.

DwORKIN, Andrea e MACKINNON, Catharine A. Pornography and civil rights: a new day for women's equality. Minneapolis, Organizing Against Pornography. 
DWORKIN, Ronald. Is there a right to pornography? Oxford Journal of Legal Studies (12), 1981, pp.177-212.

DwORKIN, Ronald. Uma questão de princípio. São Paulo, Martins Fontes, 2005 [1985].

FERRAZ JR., Tércio Sampaio et al. Garantias constitucionais à liberdade de expressão comercial. São Paulo, Conar, 2000.

FOLHA DE S. PAULO. O impulso da proibição. 30/9/2011, p.A-2.

FolHA DE S. PAUlo. Após polêmica, Caixa troca ator que interpreta Machado de Assis, 11/10/2011, p.A-7.

FOLHA DE S. PAULO. Para ministro, tentar retirar comercial de Gisele do ar é censura, 13/10/2011, p.C-7.

FOLHA DE S. PAUlO. Conar libera propaganda com Gisele Bündchen", 14/10/2011, p.C-3.

Gasparian,Taís. Publicidade e infantilização da sociedade. Folha de S. Paulo, 11/10/2011, p.A-3.

GOMES, Wilson. Opinião política na internet: uma abordagem ética das questões relativas a censura $e$ liberdade de expressão na comunicação em rede. Paper apresentado no $X$ Encontro da Associação Nacional dos Programas de Pós-Graduação em Comunicação (Compós). Brasília, 29 de maio a $1^{\circ}$ de junho de 2001.

GueRlendA, Nádia; NuBlat, Johanna e CASTRO, Cristina Moreno de. "Governo quer vetar propaganda com Gisele". Folha de S. Paulo, 29/9/2011, p.C-1.

HABERMAS, Jürgen. O futuro da natureza humana. São Paulo, Martins Fontes, 2004 [2001].

KLEIN, Naomi. Sem logo: a tirania das marcas em um planeta vendido. Rio de Janeiro, Record, 2002 [2000].

LiMA, Venício Artur de. Sobre a liberdade de expressão comercial. Observatório da Imprensa, $\mathrm{n}^{\circ} 495,2008$. Disponível no endereço: $<$ http://www.observatoriodaimprensa.com.br/news/view/sobre-aliberdade-de-expressao-comercial>. Acesso em: 8 nov 2011.

Lo PRETE, Renata. Tudo coberto. Folha de S. Paulo, 30/9/2011, p.A-4. 
Discursos sexistas no humorismo e na publicidade

LOPES, Iriny. Nenhuma mulher gosta de apanhar. IstoÉ, 12/10/2011. Entrevista a Adriana Nicacio e Octávio Costa.

MACKINNON, Catharine A. Only words. Cambridge, Harvard University Press, 1993.

MiLL, John Stuart. Sobre a liberdade. Petrópolis, Vozes, 1991 [1859].

MiLTON, John. Areopagítica: discurso pela liberdade de imprensa ao Parlamento da Inglaterra. Rio de Janeiro, Topbooks, 1999 [1644].

PATEMAn, Carole. "Women and consent". In: PATEMAn, Carole. The disorder of women. Stanford, Stanford University Press, 1989, pp.71-89.

Pondé, Luiz Felipe. A ética de Eva. Folha de S. Paulo, 10/10/2011, p.E-10.

Propp, Vladimir. Comicidade e riso. São Paulo, Ática, 1992 [1976].

RAWLS, John. Political liberalism. New York, Columbia University Press, 1993.

RocHA, Maria Eduarda da Mota. O canto da sereia: notas sobre o discurso neoliberal na publicidade brasileira pós-1990. Revista Brasileira de Ciências Sociais (64), 2007, pp.81-90.

RODRIGUES, André. A graça de um herege. Rolling Stone (56), São Paulo, 2011. Disponível em: <www.rollingstone.com.br/edicoes/56/textos/a-graca-de-um-herege > . Acesso em 3 nov. 2011.

RUBIN, Gayle. Talking sex: a conversation on sexuality and feminism. Socialist Review (11), 1981, Basingstoke, Palgrave MacMillan, pp.43-62.

SPM (Secretaria de Políticas para as Mulheres da Presidência da República). Representação ao Conselho Nacional de AutoRegulamentação Publicitária - Conar. Brasília, 2011. Disponível em: $<$ http://www.sepm.gov.br/noticias/documentos-

1/Representacao\%20ao\%20CONAR.pdf<. Acesso em: 6 nov 2011.

THOMPSON, John B. Ideologia e cultura moderna: teoria social crítica na era dos meios de comunicação de massa. Petrópolis, Vozes, 1995 [1990].

TRINDADE, Eliane. Sem pecado e com juízo. Folha de S. Paulo, 12/11/2011, p.C-6. 
VestergaARD, Torben e SCHR $\varnothing \mathrm{DER}$, Kim. A linguagem da propaganda. São Paulo, Martins Fontes, 1988 [1985].

VICTOR, Fábio. Aos 75, Verissimo troca musas pela neta. Folha de S. Paulo, 5/5/2011, p.E-6.

WOLF, Naomi. O mito da beleza: como as imagens de beleza são usadas contra as mulheres. Rio de Janeiro, Rocco 1992 [1991]. 